\title{
Stable suppression of HER-2 gene expression using siRNA increases the lysis of human ovarian carcinoma cells mediated by NK-92 cell line
}

\author{
YING ZHOU ${ }^{1,2}$, ZHIXIANG CHENG ${ }^{1,2}$, HUAIPING ZHU ${ }^{1,2}$, DINGQING FENG ${ }^{1,2}$, \\ WEIDONG ZHAO ${ }^{1,2}$, BIN LING ${ }^{1,2}$, HAIMING WEI $^{3}$ and ZHIGANG TIAN ${ }^{3}$ \\ ${ }^{1}$ Anhui Province Key Laboratory of Molecular Medicine; ${ }^{2}$ Anhui Provincial Hospital Affiliated to Anhui \\ Medical University, Hefei 230001; ${ }^{3}$ Hefei National Laboratory for Physical Sciences at Microscale \\ and School of Life Sciences, University of Science and Technology of China, Hefei 230027, P.R. China
}

Received December 5, 2007; Accepted March 11, 2008

DOI: 10.3892/or_00000162

\begin{abstract}
The overexpression and amplification of HER-2 gene is associated with the malignant biological behavior of ovarian carcinoma and these tumor cells expressing elevated levels of HER-2 appear to be resistant to the cytolysis of NK-92. In this study, we analyzed the cytolysis effects of NK-92 on human ovarian carcinoma cells (SK-OV-3) after inhibition the expression of HER-2 mRNA by siRNA. Human ovarian carcinoma cell line SK-OV-3 was transfected with siRNA-hairpin expression retroviral vector (HER-2/siRNA) designed to target HER-2 mRNA. A negative control was established utilizing a vector lacking the antisense component (HER-2/negative). The expression levels of HER-2 gene in SK-OV-3/siRNA, and SK-OV-3/negative cell lines were evaluated by semi-quantitative RT-PCR and immunohistochemistry. The growth and the early apoptosis of these cells were assayed by MTT and flow cytometry, respectively. The cytotoxicity of NK-92 against target cells was investigated by LDH. SK-OV-3/siRNA and SK-OV-3 cells were injected subcutaneously into $\mathrm{BALB} / \mathrm{c}$ nude mice respectively and NK-92 cells were intraperitoneally injected to examine the anti-tumor activity in vivo. The stable cell line (SK-OV-3/ siRNA) with a persistent silence of HER-2 was established. The inhibited expression of HER-2 gene was exhibited by semi-quantitative RT-PCR and immunohistochemistry. The suppressed proliferation and the elicitation of early apoptosis
\end{abstract}

Correspondence to: Dr Bin Ling, Anhui Provincial Hospital Affiliated to Anhui Medical University, 17 Lu-Jiang Road, Hefei City 230001, Anhui, P.R. China

E-mail: lingbin.ling@gmail.com

Abbreviations: siRNA, small interfering RNA; EGFR, epidermal growth factor receptor; NHL, non-Hodgkin's lymphoma; LGL, large granular lymphocytes

Key words: HER-2, nature killer cells, small interfering RNA, ovarian carcinoma cells were observed in SK-OV-3/siRNA cell line. NK-92 cell line can efficiently lyse the SK-OV-3/siRNA cells in vitro and significantly inhibit the growth of tumors xenografted with SK-OV-3/siRNA cells. Suppression of HER-2 gene expression using siRNA combined treatment of NK-92 presents a new strategy for NK-92 biological treatment on the HER-2 expression epithelial tumors.

\section{Introduction}

HER-2 oncogene (also called neu, erbB-2) is a member of the epidermal growth factor receptor (EGFR) family with tyrosine kinase activity. The amplification of the HER-2 gene is related to oncogenesis, malignant transformation and resistance to chemotherapeutic agents $(1,2)$. The encoding gene product p185 dimerized with other members of the EGFR family can provide mitogenic signals to tumor cells and promote tumor growth, vessel formation, invasiveness and render malignant cells resistant to apoptosis (3). HER-2 overexpression in about one-third of cases of human ovarian cancers is associated with poor prognosis (4).

Cancer therapy with NK cells can be performed by two approaches: either by activation of endogenous NK cells host (autologous) through systemic application of cytokines, or by adoptive transfer of ex vivo-expanded and activated donor (allogeneic) origin NK cells. The latter approach includes the use of cytotoxic NK cell lines that are appropriate to clinical use. NK-92 cell line was established by Hans Klingemann's group from a patient at diagnosis with non-Hodgkin's lymphoma (NHL) with large granular lymphocytes (LGL) (5), which was shown to display superior cytotoxicity against established leukemia, lymphoma and melanoma cell lines without affecting normal human cells $(6,7)$. The lytic capacity of NK-92 cell line can be improved by activation with various cytokines including interleukin (IL)-2, IL-15 and prolactin (8-11). Tumor samples $(>50 \%)$ were sensitive to NK recognition. However, solid tumor cells and several leukemia cells resistance to NK-92 lysis were also reported (12). Malignant cell lines derived from human breast, and ovarian tumors expressing high levels of receptor tyrosine kinases such as HER-2 or the closely related EGFR were completely 
resistant to NK-92-mediated lysis, with the remaining cell line being only weakly sensitive (13).

Here we have transfected SK-OV-3 cells (HER-2-positive tumor cell line) with retroviral vector HER-2/siRNA targeting in silence the expression of HER-2 gene and examined the anti-cancer effects of this NK cell clone against HER-2 silenced SK-OV-3 cell line (SK-OV-3/siRNA) both in vitro by cytotoxicity assays and in vivo by evaluating the effects of adoptive transfer of such cells on the tumor growth of SKOV-3/siRNA cells in xenografted nude mice. We found that inhibition of the expression of HER-2 might be a suitable strategy for the development of effective NK-92-based therapeutics for the treatment of HER-2-expressing epithelial carcinomas.

\section{Materials and methods}

Cell culture. SK-OV-3 (human ovarian carcinoma cell line) and NK-92 (human NK cell line) were obtained from the American Type Culture Collection (ATCC, Manassas, VA). SK-OV-3 was grown in McCoy's 5A Medium Modified supplemented with $10 \%$ fetal bovine serum, NK-92 was maintained in $\alpha$-MEM containing $100 \mathrm{U} / \mathrm{ml} \mathrm{rhIL}-2,12.5 \%$ fetal bovine serum (FBS) and $12.5 \%$ horse serum. The human leukemia cell line K-562 (Shanghai Cell Cultures) and the retroviral packaging cell line PT67 (BD Biosciences) were maintained in complete RPMI-1640 supplemented with $10 \%$ FBS. All cell lines were cultured in medium supplemented with $100 \mathrm{U} / \mathrm{ml}$ penicillin and $100 \mathrm{U} / \mathrm{ml}$ streptomycin at $37^{\circ} \mathrm{C}$ in a moist atmosphere of $5 \% \mathrm{CO}_{2}$.

Construction and production of retroviral vector carrying siRNA directed against HER-2 $m R N A$. Retroviral vector pSIREN-RetroQ was purchased from BD Biosciences and used for constructing the siRNA in the present study. The siRNA sequence (5'-GATCCGCTCTTTGAGGACAACTA TGCTTCAAGAGAGCATAGTTGTCCTCAAAGAGCTTT TTTACGCGTGAATT-3') targeting HER-2 gene was designed according to manufacturer's instruction, which contains a $21 \mathrm{bp}$ sequence matching to the coding sequence of HER-2 mRNA (with Genebank Accession number: AX384604). The synthesized HER-2 siRNA oligos were annealed and inserted into pSIREN-RetroQ downstream of U6 promoter and assigned as HER-2/siRNA. Recombinant retrovirus was packaged and produced according to manufacturer's instruction. Briefly, $1 \times 10^{5}$ packaging cells PT67 planted in a $35-\mathrm{mm}$ plate were cultured until $60-80 \%$ confluence and subjected to liposome-mediated transfection with $5 \mu \mathrm{g}$ of HER-2/siRNA vector. After $24 \mathrm{~h}$ of transfection, $1.875 \mu \mathrm{g} / \mathrm{ml}$ puromycin were added in the medium and selected for 2-3 weeks. When the stable-transfected cells were established, the supernatant containing recombinant retrovirus particles were collected and filtered with a $0.45-\mu \mathrm{m}$ filter and were used fresh. A negative control vector was also created in parallel with HER-2/siRNA and assigned as siRNA/negative that contains an unrelated sequence (5'-GATCCGTGCGTT GCTAGTACCAACTTCAAGAGATTTTTTACGCGTGA ATT-3') to HER-2 mRNA. The same protocol was used to packaging and production of siRNA/negative retrovirus particles.
Generation of $S K-O V-3$ cell lines stably expressing siRNA directed against HER-2 mRNA. SK-OV-3/siRNA and SK$\mathrm{OV}-3 /$ negative cell lines stably expressing siRNA were generated by transfection of SK-OV-3 cells with HER-2/ siRNA or siRNA/negative, respectively. Briefly, SK-OV-3 was cultured in $35-\mathrm{mm}$ plates to $70 \%$ of confluence. After removal of the culture medium and washed twice with $1 \mathrm{X}$ PBS, the cells were incubated with $2 \mathrm{ml}$ of 1:1 mixture of virus supernatant and fresh incomplete culture medium containing $1.4 \mu \mathrm{g} / \mathrm{ml}$ polybrene for $4 \mathrm{~h}$. The cells were selected with $1.875 \mu \mathrm{g} / \mathrm{ml}$ puromycin in the maintaining medium for 1 month and surviving cells (SK-OV-3/siRNA and SK-OV-3/ negative) were harvested for the study. The efficiencies of HER-2 inhibition activity by HER-2/siRNA were monitored by RT-PCR and immunohistochemical staining.

$R T-P C R$. Total RNA from the cells was extracted with TRIzol according to the manufacturer's protocol (Invitrogen). RNA $(1 \mu \mathrm{g})$ was reverse transcribed by random primer and M-MLV reverse transcriptase for $1 \mathrm{~h}$ at $37^{\circ} \mathrm{C}$. Five-fold $(5 \mu \mathrm{l})$ diluted cDNAs was then used as the templates for PCR amplification with gene-specific primers. The primers used for PCR amplification were: HER-2 sense: 5'-TGCGGCTCGTACAC AGGGACTT-3'; HER-2 antisense: 5'-TGCGGGAGAATTC AGACACCAACT-3'. ß-actin sense:5'-GTGGGGCGCCCC AGGCACCA-3'; ß-actin antisense: 5'-CTCCTTAATGTCA CGCACGATTT-3'.

Immunohistochemical staining. HER-2 antibody, the secondary antibody kit (PV6000) and liquid 3,3'-diaminobenzidine substrate (DAB) were purchased from Beijing Zhongshan Biological Technology Co. Cells $\left(1 \times 10^{5}\right)$ were seeded in $35-\mathrm{mm}$ plates which have been placed with cover glasses (24x24 mm, $0.14 \mathrm{~mm}$ thick). Twenty-four hours later the glasses were collected and washed twice with 1 X PBS and they were fixed in acetone for $10 \mathrm{~min}$. The slides were then washed 3 times with $1 \mathrm{X}$ PBS and stained with the primary antibody (1:200 dilution) and incubated at $4^{\circ} \mathrm{C}$ overnight, then the slides were rinsed twice with $1 \mathrm{X}$ PBS for $10 \mathrm{~min}$ and incubated with the corresponding secondary antibody for $30 \mathrm{~min}$ at $37^{\circ} \mathrm{C}$. The slides were rinsed twice with $1 \mathrm{X}$ PBS and incubated for $1 \mathrm{~min}$ at room temperature with $\mathrm{DAB}$. The slides were counterstained with $10 \%$ hematoxylin for $1 \mathrm{~min}$. Each immunoreaction was repeated a minimum of three times.

Apoptosis assay. ApoAlert ${ }^{\mathrm{TM}}$ Annexin V Apoptosis kit (BD Clontech) was used to analyze apoptosis. Cells $\left(5 \times 10^{5}\right)$ were collected and rinsed with $1 \mathrm{X}$ PBS, $1 \mathrm{X}$ binding buffer respectively, finally the cells resuspended in $200 \mu 11 \mathrm{X}$ binding buffer were stained with $5 \mu 1$ Annexin $\mathrm{V}$ and $10 \mu \mathrm{l}$ propidium iodide. The apoptotic cells were quantified with a BD flow cytometry using a single laser emitting excitation light at $488 \mathrm{~nm}$. Fluorescence 1 (FL1) for Annexin V, FL2 for propidium iodide.

LDH assay. The lytic capacity of NK cells was examined in LDH assay. Target cells $\left(1 \times 10^{4}\right)(\mathrm{K}-562, \mathrm{SK}-\mathrm{OV}-3, \mathrm{SK}-\mathrm{OV}-3 /$ siRNA, SK-OV-3/negative) were planted into 96-cell plates respectively and the effector cells (NK-92, irradiation dose of 8 Gray) were added into the plates at the indicated E:T cell 
A

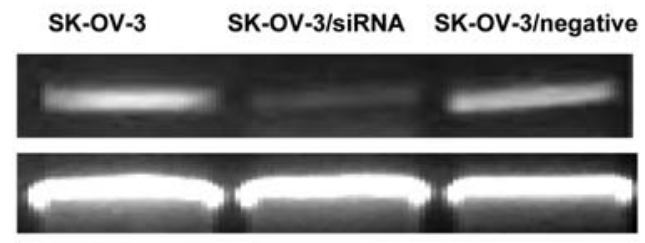

C

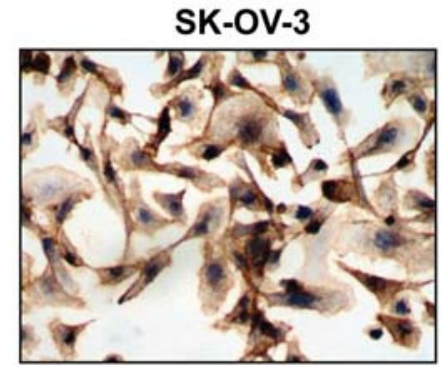

B

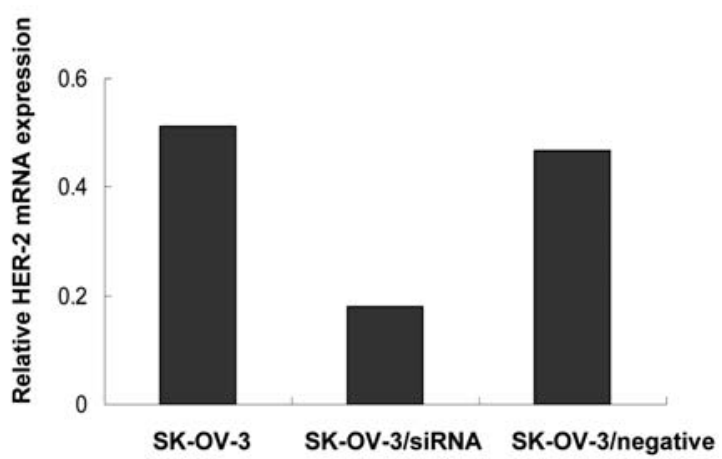

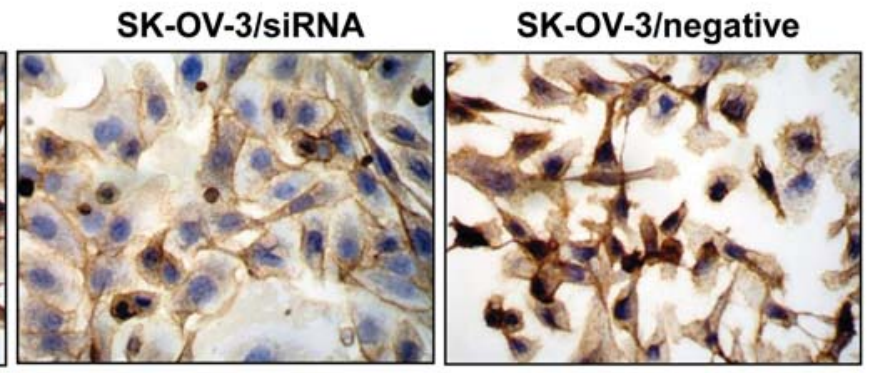

X400

Figure 1. Semi-quantitative PCR of HER-2 mRNA in SK-OV-3 cells infected with HER-2/siRNA, siRNA/negative. (A) mRNA expression in SK-OV-3 cells. SK-OV-3 cells $\left(1 \times 10^{6}\right)$ were subjected to total cell RNA extraction and RT-PCR amplification. In order to exclude the contamination, we also had a negative control group, which did not receive the RT procedure. (B) Quantitative analysis of mRNA expression from A. Y-axis indicates the rates of HER-2 mRNA and B-actin mRNA. (C) Membrane staining of SK-OV-3 cells, SK-OV-3/siRNA cells and SK-OV-3/negative cells (x400).

ratio and incubated for $4 \mathrm{~h}$ at $37^{\circ} \mathrm{C}$ in a humidified atmosphere containing $5 \% \mathrm{CO}_{2}$. The cytotoxicity activity was calculated from triplicate samples by the following formula: cytotoxic activity $($ percent $)=[$ experimental release $(\mathrm{OD})$ - spontaneous release $(\mathrm{OD})] /[$ maximal release $(\mathrm{OD})$ - spontaneous release (OD)] $\times 100 \%$. The absorbance rate at $570 \mathrm{~nm}$ was measured. All the assays were performed in triplicate.

Animal experiments. A total of 20 female mice with 18-20 g body weight and 6- to 8-week-old BALB/c athymic nude mice (Beijing experimental animal center) were divided into 4 groups for SK-OV-3/siRNA treatment by NK-92 group, SK-OV-3 treatment by NK-92 group, SK-OV-3/siRNA group and SK-OV-3 group respectively. Cells $\left(1 \times 10^{6}\right)$ were resuspended in $0.1 \mathrm{ml}$ saline for subcutaneous administration. One week later, $2 \times 10^{7}$ NK-92 cells (irradiation dose of 8 Gray) were intraperitoneally injected and the injection was conducted every week for 4 weeks. The mice were observed every week for 14 weeks after the tumor size was recorded. All the mice were housed and kept in pathogen-free environments. At the end of the experiments, the mice were sacrificed at day 98 according to the approved standard procedure. Tumor size was calculated using the formula described by Ochsenbein et al (14): tumor volume = $\pi \mathrm{abc} / 6$. Survival curve was analyzed by Kaplan-Meier method. All animal experiments were approved by the Committee of Animal Safety and Ethics of University of Science and Technology of P.R. China.
Statistical analysis. SPSS13.0 was used for statistical analysis. The significance of the differences between two groups was assayed by independent t-test. For all tests, p-values $<0.05$ were considered significant.

\section{Results}

Inhibition of the expression of HER-2 $m R N A$ and protein. HER-2/siRNA and siRNA/negative were constructed successfully by identification with digestion and sequence. HER-2 mRNA inhibition rate of SK-OV-3/siRNA is $64.79 \%$ compared with the parental cell, and the inhibition rate is $61.4 \%$ compared with SK-OV-3/negative cells (Fig. 1A and B). HER-2 protein was also repressed markedly in SKOV-3/siRNA cells (Fig. 1C).

The proliferation of $\mathrm{SK}-\mathrm{OV}-3$ cells is inhibited by HER-2 silencing. Because HER-2 is known to stimulate cell growth, we examined the proliferation of SK-OV-3 cells in which HER-2 has been silenced by retrovirus-mediated siRNA. Proliferation of SK-OV-3/siRNA cells, as indicated by MTT, was substantially inhibited on day 4 and day $6(\mathrm{p}<0.05$, Fig. 2A).

Increased apoptosis in HER-2-silenced cells. After inhibition the expression of HER-2, we examined the early apoptotic cell percentages of the cell lines by Annexin V fluorescein and propidium iodide staining. The number of early apoptotic cells 
A

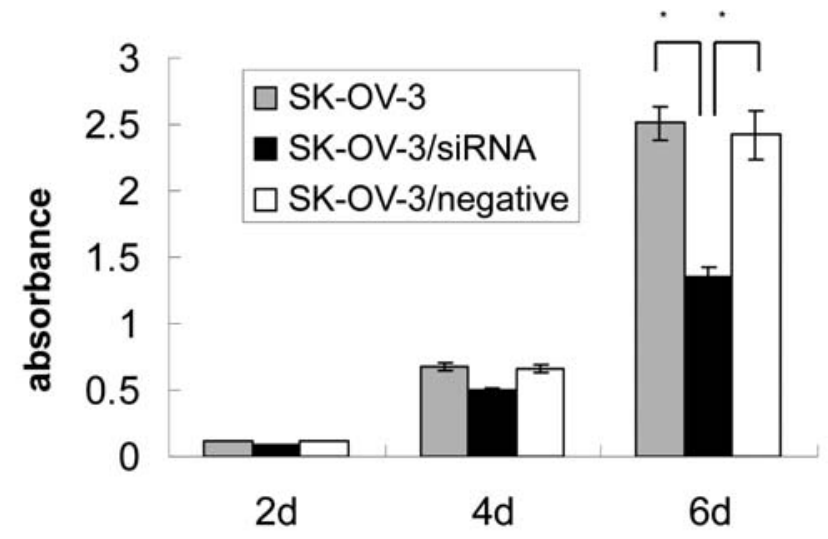

C

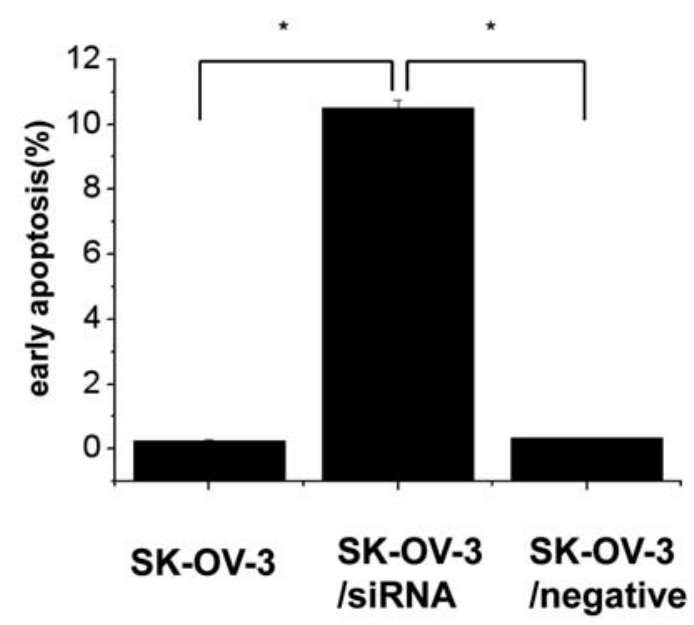

B

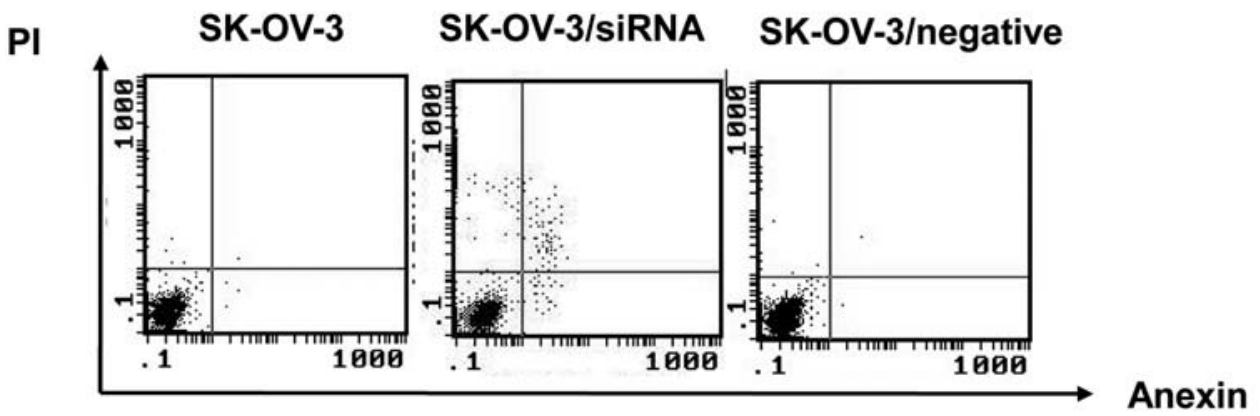

Figure 2. (A) The proliferation of SK-OV-3 is inhibited after infection with HER-2/siRNA. Cells (1x10 $)$ of SK-OV3, SK-OV-3/siRNA, SK-OV-3/negative were seeded into a 96 -well, respectively to be measured by MTT with a $570 \mathrm{~nm}$ filter after culture of 2,4 or 6 days ( ${ }^{*} \mathrm{P}<0.05 \mathrm{vs}$. SK-OV-3/negative and SK-OV3). (B) Flow cytometry analysis of apoptosis by Annexin V (x-axis) and propidium iodide (y-axis) staining. (C) Quantitative analysis of early apoptotic cells from $\mathrm{B}\left({ }^{*} \mathrm{P}<0.05\right.$ vs. SK-OV-3/negative and SK-OV-3).

increased in SK-OV-3/siRNA cells as compared with SKOV-3/negative cells and the parental cells (Fig. 2B and C). In quantitative terms, the percentage of early apoptotic cells in SK-OV-3/siRNA cells was $10.5 \pm 0.25 \%$; the corresponding values in the control cells and paternal cells were all $<1 \%$ $(\mathrm{p}<0.01)$.

Cytotoxicity. LDH assay was performed to determine whether the expression of HER-2 affect the cytotoxicity of NK-92. SK-OV-3, SK-OV-3/siRNA and SK-OV-3/negative were used as the target cells and K-562 was used as sensitive target cell of NK-92. Assay was conducted at E/T ratios of $1: 1,5: 1$, 10:1 and 20:1. The lytic capacity of NK-92 against SK-OV-3 was low $(<21 \%$, Fig. 3A) even at $\mathrm{E} / \mathrm{T}$ ratios of $20: 1$, in contrast to sensitive target cell K-562 (Fig. 3A). Therefore, we next adopted E/T ratios of 20:1 to examine the cytolytic activity of NK-92 against target cells in vivo and in vitro. The NK resistance was overcome by HER-2/siRNA, killing SKOV-3/siRNA by NK-92 was markedly higher (45\%) than the parental cells (21\%) and SK-OV-3/negative cells (24\%) at E/T ratios of 20:1 (Fig. 3B) $(\mathrm{p}<0.05)$.

NK-92 cells inhibit the in vivo growth of HER-2 silencing tumor cells. In order to investigate whether NK-92 can slow down HER-2 silencing tumor cells in vivo, SK-OV-3/siRNA and SK-OV-3 cells were injected subcutaneously into BALB/c nude mice. NK-92 cells were intraperitoneally injected to inhibit the growth of tumors. All animal experiments were approved by the Committee of Animal Safety and Ethics of University of Science and Technology of P.R. China. As shown in Fig. 4A, the tumor volumes of SK-OV-3 treatment by NK-92 group, SK-OV-3/siRNA treatment by NK-92 group were $75 \mathrm{~mm}^{3}$ and $3 \mathrm{~mm}^{3}$ respectively at week 6 , the differences between these two groups were statistically significant $(\mathrm{P}<0.01)$. The tumor mass of SK-OV-3/siRNA treatment by NK-92 group showed drastically suppression $(0.0633 \pm 0.01528 \mathrm{~g})$ at day 98 (Fig. 4B and C), compared with the mass of SK-OV-3 treatment by NK-92 group $(1.0133 \pm 0.23756 \mathrm{~g})(\mathrm{P}<0.01)$. The survival rates of mice in SK-OV-3/siRNA treatment by NK-92 group and in SK-OV-3 treatment by NK-92 group were $100 \%$ and $40 \%$ respectively at day 98 (Fig. 4D). These results suggest that HER-2 silencing can augment the inhibition effects of solid tumors overexpression HER-2 by NK-92.

\section{Discussion}

HER-2 is a member of the EGFR-related family of receptor tyrosine kinases. HER-2 gene amplification and P185 protein overexpression observed in many epithelial original tumors have been related with a more aggressive course of tumor $(15,16)$. A crucial role for HER-2 as a therapeutic target has been shown previously (16) and numerous strategies have been developed established the application of antibodies against HER-2 for heading for cancer treatment (17-19). NK-92 cells present functional characteristics of activated 

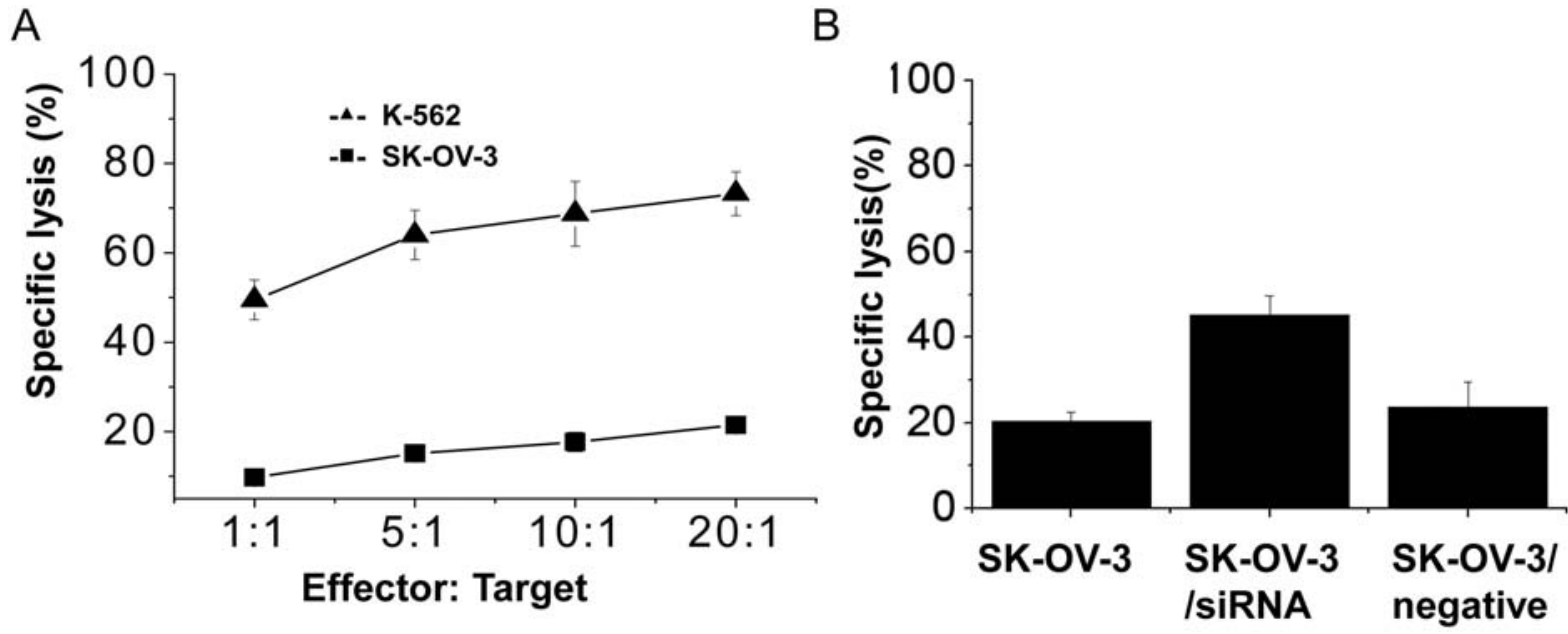

Figure 3. Inhibition the expression of HER-2 increases the cytotoxicity of NK-92 cells (irradiation dose of 8 Gray) against SK-OV-3 cells using LDH assays. (A) The cytotoxicity of NK-92 against SK-OV-3 at different E/T ratios. (B) The lytic capacity of NK-92 against SK-OV-3, SK-OV-3/siRNA and SK-OV-3/ negative at $\mathrm{E} / \mathrm{T}$ ratio of 20:1.

A

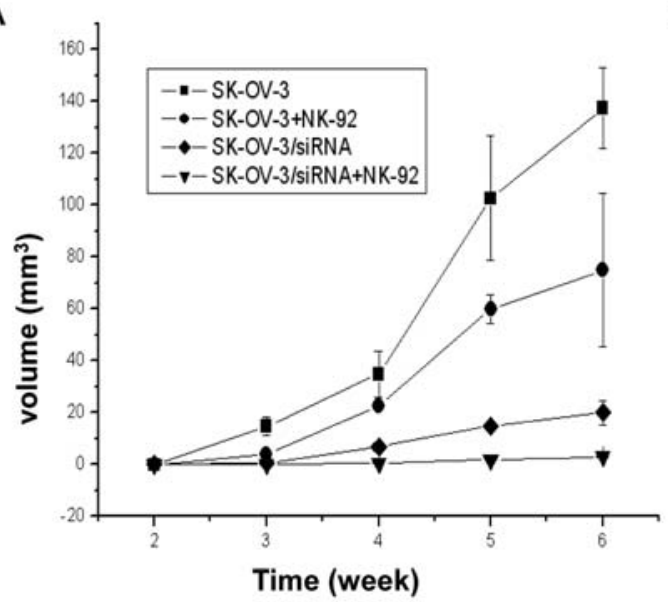

B

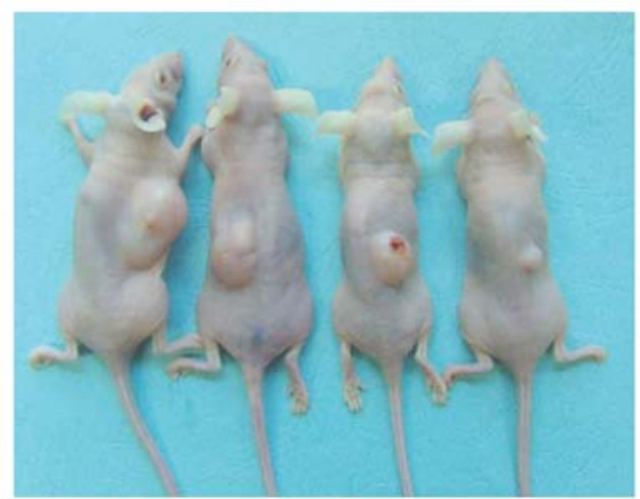

D

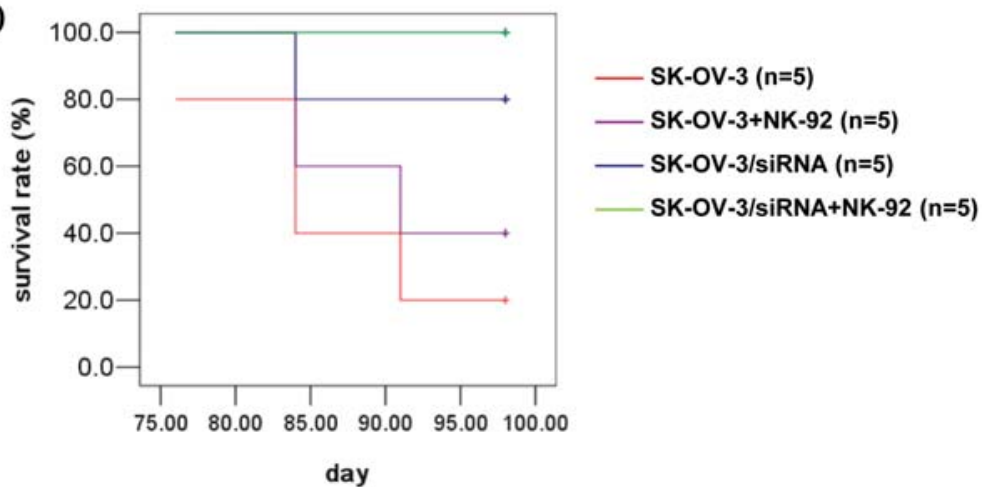

Figure 4. Tumor growth in HER-2/siRNA-infected cells treated by NK-92 cells (irradiation dose of 8 Gray). Cells (1x10 $)$ were subcutaneously injected into nude mice housed in pathogen-free environments. One week later, $2 \times 10^{7} \mathrm{NK}-92$ cells were intraperitoneally injected and the injection was conducted every week for 4 weeks. The mice were checked every week and killed at day 98. (A) The tumor volumes of SK-OV-3/siRNA treatment by NK-92 group were drastically smaller than that of SK-OV-3 treatment by NK-92 group at week $6\left({ }^{*} \mathrm{P}<0.01\right.$, SK-OV-3/siRNA treatment by NK-92 group vs. SK-OV-3 treatment by NK-92 group). (B) Representative mice from SK-OV-3 group, SK-OV-3 treatment by NK-92 group, SK-OV-3/siRNA group, SK-OV-3/siRNA treatment by NK-92 group respectively showing tumors on day 98 (from left to right). (C) The tumor weights of SK-OV-3/siRNA treatment by NK-92 group were slightly lighter at day 98 , compared with SK-OV-3 treatment by NK-92 group $\left({ }^{*} \mathrm{P}<0.01\right.$ SK-OV-3/siRNA treatment by NK-92 group vs. SK-OV-3 treatment by NK-92 group). (D) The survival curves of different group mice.

NK cells, which express typical NK-cell surface receptors, but lack FccRIII (5). The high-endogenous cytotoxic potential of NK-92 is most likely attributable to the absence of inhibitory NK cell receptors with the exception of KIR2DL4 $(20,21)$, which through binding to HLA antigens on target cells inhibit NK cell cytolytic activity (22). The anti- 
cancer effects of NK-92 on leukemia and melanoma cell lines have been established in vivo and in vitro $(7,23,24)$, however, the proportion of NK-92-sensitive cancer cells derived from solid tumors appears to be significantly lower, especially tumor cell lines and primary cancer cells originating from human breast, and ovarian cell carcinomas expressing elevated levels of receptor tyrosine kinases such as HER-2 or the closely related EGFR were completely resistant to NK-92-mediated lysis (13).

Although the mechanisms of tumors expressing elevated levels of receptor tyrosine kinases resistant to NK-92 killing were not clear, some researchers have constructed modified NK-92 cells expressing a chimeric antigen receptor specific for the tumor-associated HER-2 antigen to directly elicit NK-92 cytotoxicity to HER-2 expressing tumor cells. Significant cytolytic activity of NK-92-scFv(FRP5)- $\zeta$ cells could be displayed against several HER-2 expressing primary and established carcinoma cells (including breast tumor, ovarian and squamous cell tumor), which were otherwise resistant to parental NK-92 cells (25-27).

In this study, we explored retrovirus-mediated siRNA against HER-2 substantially to reduce the expression of HER-2 mRNA and protein, which brought out the cells of early apoptosis, thus the percentage of early apoptotic cells in SK-OV-3/siRNA cells was markedly enhanced, compared with the parental cells and the control cells. NK-92-mediated SK-OV-3 killing in vitro was low even if at E:T of 20:1, however, while the expression of HER-2 in target cells was inhibited, the cytotoxicity of NK-92 was enhanced significantly. NK-92 cells were irradiated at the dose of 8 Gray, according to our previous study to prevent engraftment of the tumorigenic NK-92 cells into the host but retain their cytotoxic capacity (28). As for the animal experiments, the tumor growth of SK-OV-3 cells knockdown HER-2 expression by siRNA was markedly slow, compared with the tumors of SK-OV-3; when using intraperitoneal injection of NK-92 cell lines, the further significant inhibition effects on these tumors were shown. In this study, we also performed in vivo experiments to SK-OV-3/negative cells, the results for SK-OV-3/negative were similar to those of SK-OV-3 cells, demonstrating that the application of siRNA against HER-2 can reverse the resistance of SK-OV-3 cells to NK-92-mediated lysis. The reason of which might be that HER-2 plays an important role in the mediating growth factor signaling, such overexpression produces an over-activated downstream signaling pathway, resulting in deregulated cell proliferation, evasion from apoptosis, angiogenesis, migration, and metastasis. When overexpression of HER-2 was inhibited by siRNA, its malignant biological behavior was probably reduced. Meanwhile, when the overexpression of HER-2 was reversed, the number of SK-OV-3 cells with early apoptosis starkly increased and the apoptosis cells were more sensitive to NK-92 mediated lysis. Yang et al also has reported that use of siRNA against HER-2 could activate apoptotic pathways in SK-OV-3 cell line and the percentages of apoptotic cells in which HER-2 had been silenced were $11 \%$ for SK-OV-3 cells in their study (3).

In support of our conclusions, it has been shown previously that HER-2-overexpressing breast and ovarian cell lines were more resistant to NK-mediated lysis than non-expressing (or
HER-2 low) targets $(29,30)$. Taken together, these results suggest that endogenously processed HER-2 protein may contribute to the resistance of HER-2-overexpressing tumor cells to NK-mediated lysis. Suppression of HER-2 gene expression using siRNA combined treatment of NK-92 presents a hopeful strategy for NK-92 biological treatment on the HER-2 expression epithelial tumors.

\section{Acknowledgements}

This study was supported by the Hi-Tech Research and Development Program of P.R. China (\#2002AA216151), the Anhui Provincial Natural Science Foundation project (\#20050430715), the Anhui Provincial Educational Department Natural Science Foundation project (\#2005KJ347ZC), the Chinese National Natural Science Foundation project (\#30471805), the Natural Science Foundation of Anhui Provincial Educational Department, P.R. China (\#2006KJ080C).

\section{References}

1. Slamon DJ, Godolphin W, Jones LA, Holt JA, Wong SG, Keith DE, et al: Studies of the HER-2/neu proto-oncogene in human breast and ovarian cancer. Science 244: 707-712, 1989.

2. Yarden Y and Sliwkowski MX: Untangling the ErbB signalling network. Nat Rev Mol Cell Biol 2: 127-137, 2001.

3. Yang G, Cai KQ, Thompson-Lanza JA, Bast RC Jr and Liu J: Inhibition of breast and ovarian tumor growth through multiple signaling pathways by using retrovirus-mediated small interfering RNA against Her-2/neu gene expression. J Biol Chem 279: 4339-4345, 2004.

4. Skirnisdottir I, Sorbe B and Seidal T: The growth factor receptors HER-2/neu and EGFR, their relationship, and their effects on the prognosis in early stage (FIGO I-II) epithelial ovarian carcinoma. Int J Gynecol Cancer 11: 119-129, 2001.

5. Gong JH, Maki G and Klingemann HG: Characterization of a human cell line (NK-92) with phenotypical and functional characteristics of activated natural killer cells. Leukemia 8: 652-658, 1994.

6. Igarashi T, Wynberg J, Srinivasan R, Becknell B, McCoy JP Jr, Takahashi Y, et al: Enhanced cytotoxicity of allogeneic NK cells with killer immunoglobulin-like receptor ligand incompatibility against melanoma and renal cell carcinoma cells. Blood 104: 170-177, 2004.

7. Yan Y, Steinherz P, Klingemann HG, Dennig D, Childs BH, McGuirk J, et al: Antileukemia activity of a natural killer cell line against human leukemias. Clin Cancer Res 4: 2859-2868, 1998.

8. Son YI, Dallal RM, Mailliard RB, Egawa S, Jonak ZL and Lotze MT: Interleukin-18 (IL-18) synergizes with IL-2 to enhance cytotoxicity, interferon-gamma production, and expansion of natural killer cells. Cancer Res 61: 884-888, 2001.

9. Sun R, Li AL, Wei HM and Tian ZG: Expression of prolactin receptor and response to prolactin stimulation of human $\mathrm{NK}$ cell lines. Cell Res 14: 67-73, 2004.

10. Uharek L, Zeis M, Glass B, Steinmann J, Dreger P, Gassmann W, et al: High lytic activity against human leukemia cells after activation of allogeneic NK cells by IL-12 and IL-2. Leukemia 10: 1758-1764, 1996.

11. Zhang J, Sun R, Wei H, Zhang J and Tian Z: Characterization of interleukin-15 gene-modified human natural killer cells: implications for adoptive cellular immunotherapy. Haematologica 89: 338-347, 2004.

12. Romanski A, Bug G, Becker S, Kampfmann M, Seifried E, Hoelzer D, et al: Mechanisms of resistance to natural killer cellmediated cytotoxicity in acute lymphoblastic leukemia. Exp Hematol 33: 344-352, 2005.

13. Daldrup-Link HE, Meier R, Rudelius M, Piontek G, Piert M, Metz S, et al: In vivo tracking of genetically engineered, antiHER2/neu directed natural killer cells to HER2/neu positive mammary tumors with magnetic resonance imaging. Eur Radiol 15: 4-13, 2005. 
14. Ochsenbein AF, Sierro S, Odermatt B, Pericin M, Karrer U, Hermans J, et al: Roles of tumor localization, second signals and cross priming in cytotoxic T-cell induction. Nature 411: 1058-1064, 2001

15. Menard S, Pupa SM, Campiglio M and Tagliabue E: Biologic and therapeutic role of HER2 in cancer. Oncogene 22: 6570-6578, 2003.

16. Camilleri-Broet S, Hardy-Bessard AC, Le Tourneau A, Paraiso D, Levrel O, Leduc B, et al: HER-2 overexpression is an independent marker of poor prognosis of advanced primary ovarian carcinoma: a multicenter study of the GINECO group. Ann Oncol 15: 104-112, 2004.

17. Carson WE, Parihar R, Lindemann MJ, Personeni N, Dierksheide J, Meropol NJ, et al: Interleukin-2 enhances the natural killer cell response to Herceptin-coated Her2/neu-positive breast cancer cells. Eur J Immunol 31: 3016-3025, 2001.

18. Pusztai L and Esteva FJ. Continued use of trastuzumab (herceptin) after progression on prior trastuzumab therapy in HER-2-positive metastatic breast cancer. Cancer Invest 24: 187-191, 2006.

19. Ross JS and Gray GS: Targeted therapy for cancer: the HER-2/ neu and Herceptin story. Clin Leadersh Manag Rev 17: 333-340, 2003.

20. Tam YK, Miyagawa B, Ho VC and Klingemann HG: Immunotherapy of malignant melanoma in a SCID mouse model using the highly cytotoxic natural killer cell line NK-92. J Hematother 8: 281-290, 1999.

21. Tonn T, Becker S, Esser R, Schwabe D and Seifried E: Cellular immunotherapy of malignancies using the clonal natural killer cell line NK-92. J Hematother Stem Cell Res 10: 535-544, 2001.

22. Burshtyn DN, Scharenberg AM, Wagtmann N, Rajagopalan S, Berrada K, Yi T, et al: Recruitment of tyrosine phosphatase HCP by the killer cell inhibitor receptor. Immunity 4: 77-85, 1996.
23. Maki G, Tam YK, Berkahn L and Klingemann HG: Ex vivo purging with NK-92 prior to autografting for chronic myelogenous leukemia. Bone Marrow Transplant 31: 1119-1125, 2003.

24. Klingemann HG, Wong E and Maki G: A cytotoxic NK-cell line (NK-92) for ex vivo purging of leukemia from blood. Biol Blood Marrow Transplant 2: 68-75, 1996.

25. Suck G: Novel approaches using natural killer cells in cancer therapy. Semin Cancer Biol 16: 412-418, 2006.

26. Uherek C, Tonn T, Uherek B, Becker S, Schnierle B, Klingemann $\mathrm{HG}$, et al: Retargeting of natural killer-cell cytolytic activity to ErbB2-expressing cancer cells results in efficient and selective tumor cell destruction. Blood 100: 12651273, 2002.

27. Demirtzoglou FJ, Papadopoulos S and Zografos G: Cytolytic and cytotoxic activity of a human natural killer cell line genetically modified to specifically recognize HER-2/neu overexpressing tumor cells. Immunopharmacol Immunotoxicol 28: 571-590, 2006.

28. Chen G, Ling B, Zhu HP, Zhao WD, Wang QH, Zhang HY, et al Effect of natural killer cell line NK-92 against human ovarian carcinoma cells in vitro and in vivo. Zhonghua $\mathrm{Fu}$ Chan $\mathrm{Ke} \mathrm{Za}$ Zhi 40: 476-479, 2005

29. Shahied LS, Tang Y, Alpaugh RK, Somer R, Greenspon D and Weiner LM: Bispecific minibodies targeting HER2/neu and CD16 exhibit improved tumor lysis when placed in a divalent tumor antigen binding format. J Biol Chem 279: 53907-53914, 2004.

30. Wiltschke C, Tyl E, Speiser P, Steininger A, Zeillinger R, Kury F, et al: Increased natural killer cell activity correlates with low or negative expression of the HER-2/neu oncogene in patients with breast cancer. Cancer 73: 135-139, 1994. 